\title{
Study on the Supply and Demand Balance of Enterprise Human Resources Based on Statistical Prediction and Analysis
}

\author{
Shijun Jiang ${ }^{1}$ and Chuanshu $\mathrm{Zhu}^{2}$ \\ ${ }^{1}$ Academic Affairs Office, Chongqing College of Finance and Economics, 402160 Chongqing, China \\ ${ }^{2}$ Personnel Section, Chongqing College of Finance and Economics, 402160 Chongqing, China
}

\begin{abstract}
The purpose of this study is to explore the relationship between supply and demand of human resources in enterprises. We know that the human resources departments in enterprises need to recruit staff from society every year to maintain scientific development of enterprises. But how to find the relationship between enterprise internal supply and actual demand is the real concern for many enterprises. At the beginning of the year, the implementation of recruitment is based on historical data, which requires a scientific and reasonable forecast to lay the foundation for optimization of human resources allocation. This article uses the trend equation fitting to forecast and research the actual demand of human resources, applies Markoff prediction model to forecast and research the internal supply of human resources, meanwhile uses staff flow data of an enterprise from 2006 to 2013 to conduct an empirical analysis of the reliability and science of model algorithm, which provides a theoretical basis for the prediction of the balance of supply and demand for human resources in enterprises.
\end{abstract}

Keywords. supply and demand of human resources; trend equation fitting; Markoff model; state matrix

\section{Introduction}

Rational allocation of human resources is absolutely necessary for the development of an enterprise, and the foundation of human resource allocation is to solve the problem of the supply and demand balance of enterprise human resources. This article, in order to explore the forecasting model of supply and demand of enterprise human resources, puts forward the idea of predicting supply and demand of human resources by application of trend equation model and Markoff model, expecting to lay the foundation for optimizing the allocation of human resources.

Many scholars have made efforts to study for the supply and demand of enterprise human resources, and with the methods of natural science infiltrating into management science, the human resources management has received a more perfect technical supports, among which: Lai Xianghui (2013), through the analysis of the connotation of human resource planning and the current status of human resource planning of China's enterprises, proposed model and application of strategic human resource planning $^{[1]}$; Zhang Ning et al (2013) introduced multiple linear regression algorithm and the Markoff model into the supply and demand forecast of human resources, and proposed an improved decision method of forecasting supply and demand of human resource. She used C\#.net language to develop the corresponding decision support system, and conducted relevant verification and experiments, which proved the effectiveness of improved method. Li Suping et al (2013), through mathematical method, constructed model system of human resource demand that can control the total employment, configuration of employment, optimization of employment and standardization of labor policy, found out the relationship and rules between staff development in power grid enterprises, scale of business increase, production efficiency and economic benefits, took into account the supply of internal and external talent market to specify effective replacement strategy, which laid a solid foundation of human resources for the sustainable and healthy development of the enterprise ${ }^{[3]}$.

This article analyzes the factors affecting the supply and demand of human resources in enterprises on the basis of previous research, and provides a forecasting method of internal supply and actual demand, aiming at making contribution for Chinese enterprises to optimize the allocation of human resources.

\section{Analysis of the factors affecting the supply and demand of human resources}

Cai Wenling (2013) points out, presently as a most important resource of enterprise development, acquisition 
and demand-meeting intensity of human resources are very important. Supply and demand of human resources includes prediction of human resource and the supply of human resources. How to find a talent and get it used by enterprise is of great significance ${ }^{[4]}$.

This chapter makes an analysis on the factors influencing the demand and supply of human resources, expecting to lay the foundation for the prediction of the optimization of enterprise human resources.

The factors affecting demand of human resources can be analyzed microcosmically and macroscopically, as shown below:

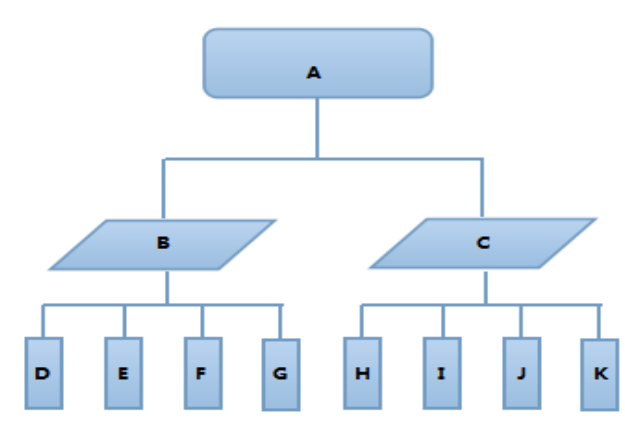

A. Factors affecting the demand of human resource

B. Microcosmic factors

C. Macro factors

D. Enterprise strategy

E. Enterprise management status

F. The level of enterprise management

G. The staff turnover rate

H. Economic environment

I. Political and legal environment

J. The labor market

$\mathrm{K}$. Technological progress and the external competition

Factors affecting human resource supply can be analyzed from two aspects of the internal and external enterprises, as shown below:

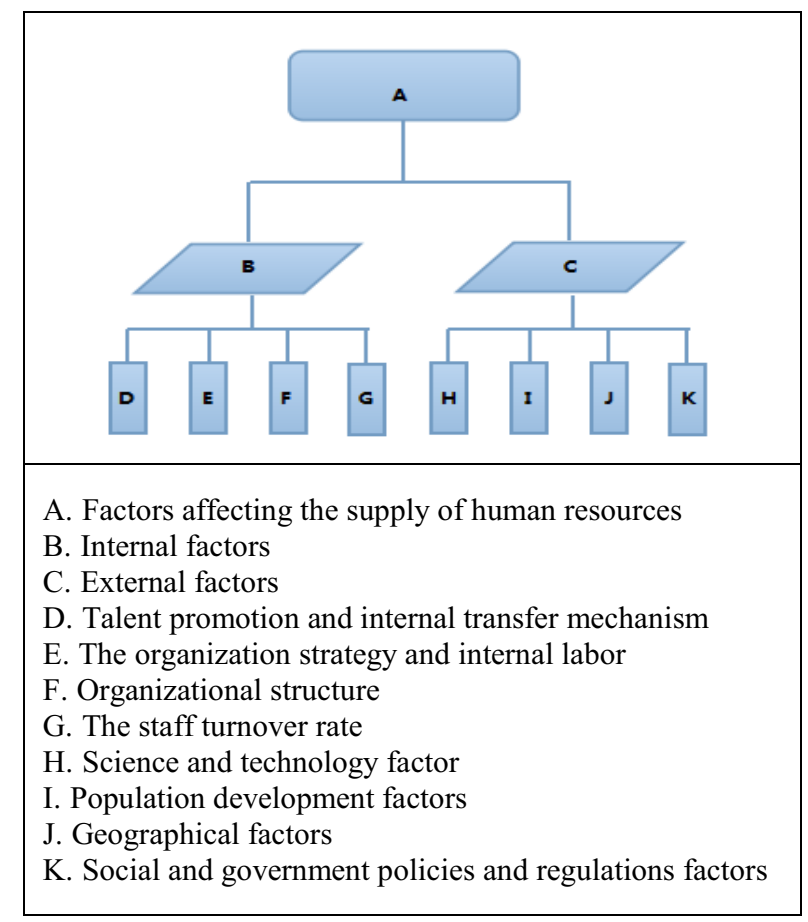

Pan Zhu (2013) points out, the demand forecast of enterprise human resources has a variety of methods of analysis. In prediction of human resource demand, enterprises should consider all the complex and varied factors, such as the target of the enterprise and business strategy, changes in production condition, work design or in organizational structure or others. Furthermore, the correlation between the various factors and the prediction results is difficult to use quantitative method to express, which is the nonlinear mapping relationship with mutual restriction $^{[5]}$.

Usually there are four kinds of methods for the prediction of human resource demand:

1) Subjective judgment

2) Delphi method

3) Ratio analysis

4) Scatter diagram

Prediction method used in this article is the statistical method based on scatter diagram method, which uses trend equation fitting that is also called linear regression method. Usually, there are three kinds of the following methods to forecast the supply of human resources:

1) Supply matrix prediction method.

2) Succession planning method.

3) Markoff chains forecasting method.

Forecasting methods of human resource supply used in the article is the Markoff model

\section{Prediction model of supply and de- mand of human resource}

\subsection{Trend equation fitting model}

The calculation principle of trend equation fitting model is actually a statistical regression analysis, which considers the time variables in the time sequence as independent variables in regression analysis, and uses the actual data in previous years to compose a trend line that should minimize the quadratic sum of the distance of each point in original series to the curve.

The basic principle of statistical regression algorithm is to reach the divisors as shown in two equations in formula (1), for the purpose of making mean deviation between the actual value of original series and the function value of trend equation a zero sum, and minimizing the total value of sum of deviation square when the average deviation reaches zero sum.

$$
\left\{\begin{array}{l}
\sum_{i=1}^{n}\left(y_{i}-\hat{y}_{i}\right)=0 \\
Q=\sum_{i=1}^{n}\left(y_{i}-\hat{y}_{i}\right)^{2} \rightarrow \mathrm{Min}
\end{array}\right.
$$

In formula (1), $y_{i}$ represents the $\mathrm{i}^{\text {th }}$ actual sequence value, and $\hat{y}_{i}$ represents the function value of trend equation to which the $i^{\text {th }}$ actual value corresponds.

Usually, the trend equation can be divided into three fitting methods, namely linear, parabolic and exponential form. The final fitting equations for three trend equations 
above are respectively in the form of formula (2), formula (3) and (4).

$$
\begin{aligned}
& \hat{Y}_{t}=a+b t \\
& \hat{Y}_{t}=a+b t+c t^{2} \\
& \hat{Y}_{t}=a b^{t}
\end{aligned}
$$

Known from the formula (2) to formula (4), the required parameters for three types of trend equations are varied, among which, two parameters are required to be determined for formula (2), and its calculation formula is as shown in formula (5); a, b and c parameters are required to be determined for formula (3), and its calculation formula is as shown in formula (6); $a$ and $b$ parameters are required to be determined for formula (4), But the formula (3) can be transformed into the form shown in formula (7), then use the methods shown in formula (5) to determine two parameters, namely $A=\ln a$ and $B=\ln b$, and finally conduct anti-calculation for parameters after conversion to get $a=\exp A$ and $b=\exp B$. The final exponential trend equation shown in formula(4) will be obtained.

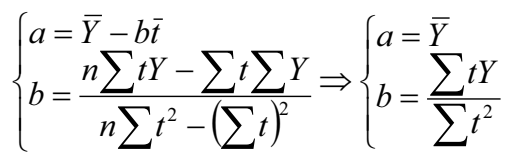

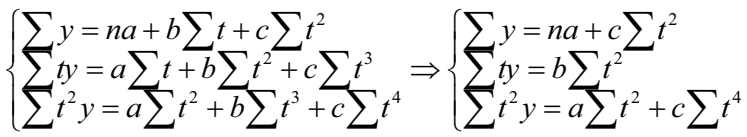

$\hat{Y}_{t}=a b^{t} \Leftrightarrow\left\{\begin{array}{l}A=\ln a ; B=\ln b ; \hat{y}_{t}=\ln \hat{Y} \\ \hat{y}_{t}=A+B t\end{array}\right.$

Guo Hui (2014) points out, methods for prediction of human resource demand are divided into two types, namely qualitative forecast and quantitative forecast, among which the method for the quantitative prediction of human resource demand will require the statistical thinking and methods to be applied to the forecasting of human resource demand, and use the least square method, take the time $t$ as the explanatory variables and utilize the regression equation that takes the inspected indexes as explained variables to predict the human resource demand. When the scatter diagram of time sequence is presented in some curve shape, it indicates that the development of the phenomenon is showing a nonlinear trend, which is required to be coordinated with the proper trend $^{[6]}$.

However, in the actual analysis and forecasting of human resource demand in business, the application of methods of subjective judgment, Delphi $\mathrm{Fa}$ and trend equation fitting method with quantitative analysis should be combined. This is because If we apply the trend equation fitting in spite of rigid enterprise's actual situation, it may cause the waste or insufficiency of human resources. Overall, the statistical analysis method used in the forecast of enterprise human resources demand is an effective means of technical analysis, and also an important means to provide distinctive materials for the optimization of enterprise human resources. This article uses linear method in trend equation fitting to conduct fitting prediction for time sequence for the total number of employees in an enterprise from 2006 to 2013. The prediction results will be shown in the next chapter.

\subsection{Markoff model}

Wu Jing and other people(2005) point out, Markoff forecasting method is a method of using the statistical principle to forecast the supply of human resources within enterprises. The basic idea is to find out the changes in human resources of enterprises in the past few years through collection of specific historical data to forecast the future trend of human resource. Markoff prediction method is actually a kind of transition probability matrix, using statistical techniques to predict future changes in human resources. In this way the overall description of situation of outflow, inflow and internal flow for the enterprise employees in this way may be used as a basis for prediction of internal supply of human resources ${ }^{[7]}$.

The definition of Markoff chain is based on a random sequence under the following two conditions, and the random sequence is $X_{0}, X_{1}, \cdots$ derived from the probability space $(\Omega, F, P)$.

Condition 1. The state space $\left\{X_{n}: n \geq 0\right\}$ is a collection of countable.

Condition 2. For any $n$ and state $i_{0}, i_{1}, \cdots, i_{n+1}$ that satisfy the formula (8) will definitely lead to existence of formula (9).

$$
\begin{aligned}
& P\left\{X_{0}=i_{0}, X_{1}=i_{1}, \cdots, X_{n}=i_{n}\right\} \geq 0 \\
& P\left\{X_{n+1}=i_{n+1} \mid X_{0}=i_{0}, \cdots, X_{n}=i_{n}\right\}=P\left\{X_{n+1}=i_{n+1} \mid X_{n}=i_{n}\right\}
\end{aligned}
$$

Markoff chain has non-consequent nature, namely it's only related to the previous event. For any $\mathrm{m}, \mathrm{n}$ and state $\mathrm{i}, \mathrm{j}$, the existence of $P\left\{X_{n}=i\right\}>0, P\left\{X_{m}=i\right\}>0$ will definitely lead to that of $P\left\{X_{n+1}=j \mid X_{n}=i\right\}=P\left\{X_{m+1}=j \mid X_{m}=i\right\}$, by which the Markoff chain can be considered as homogeneous, and $P_{i j}=P\left\{X_{n+1}=j \mid X_{n}=i\right\}$ as state transition probability of $\left\{X_{n}: n \geq 0\right\}$.

The probability that a particle sets out from the state $i$ at the time $n$, and then is transferred to state $j$ at the time $n+1$ shall be $P_{i j}$. If $i, j$ are changed in the state space $E$, transfer matrix are usually defined as shown in formula(10).

$$
\mathbf{P}(1)=\left[\begin{array}{cccc}
p_{11} & p_{12} & \cdots & p_{1 n} \\
p_{21} & p_{22} & \cdots & p_{2 n} \\
\cdots & \cdots & \cdots & \cdots \\
p_{n 1} & p_{n 2} & \cdots & p_{n n}
\end{array}\right] \Rightarrow \mathbf{P}(k)=\left[\begin{array}{cccc}
p_{11}(k) & p_{12}(k) & \cdots & p_{1 n}(k) \\
p_{21}(k) & p_{22}(k) & \cdots & p_{2 n}(k) \\
\cdots & \cdots & \cdots & \cdots \\
p_{n 1}(k) & p_{n 2}(k) & \cdots & p_{n n}(k)
\end{array}\right]
$$


Among which, $P_{i j} \geq 0 ; \sum_{j=1}^{n} P_{i j}=1$ and $P_{i i}, P_{j j}$ represents retention probability, $\mathbf{P}(1)$ the step 1 st transition probability matrix and $\mathbf{P}(k)$ the step $\mathrm{k}$ transfer matrix. $\mathbf{P}(1)$ and $\mathbf{P}(k)$.

$$
\mathbf{P}(k)=\mathbf{P}(1) \cdot \mathbf{P}(k-1)=\mathbf{P}^{k}(1)
$$

Markoff prediction model as shown below can be established by using the state transition probability and the initial state of system:

First of all, we need to set the initial state of system to $\mathrm{k}=0$. The probability that the system goes through $\mathrm{k}$ times of transfer and arrives at the state as $S_{i}(k)$. At the time, $\sum S_{i}(k)=1$ is existent. Then the content shown in formula (12)is obtained according to the Chapman Kerr Mo Gono $\mathrm{J}$ equation, and convert it into a the expression vector shown in formula (13). Finally a recursive formula can be obtained as shown in formula (14). Thus we get the Markoff prediction model for system state.

$$
\begin{aligned}
& S_{j}(k+1)=S_{j}(k) \cdot p_{i j},(k=0,1,2, \cdots) \\
& \mathbf{S}(k+1)=\mathbf{S}(k) \cdot \mathbf{P},(k=0,1,2, \cdots) \\
& \mathbf{S}(k+1)=\mathbf{S}(0) \cdot \mathbf{P}^{k+1},(k=0,1,2, \cdots)
\end{aligned}
$$

This article uses Markoff prediction model to conduct the prediction and analysis on the supply of human resource, and its specific steps are as follows:

STEP1. According to the historical data in enterprise, the
average probability of flow from this position to another
position for the employee can be obtained.
STEP2. The establishment of personnel change matrix
STEP3. Prediction of number of people that can be
supplied in the second year to complete the supply
forecasting of human resources in accordance with the type
of position and number in enterprise at the end of the year,
as well as the personnel change matrix in STEP2..

\section{Empirical analysis on prediction of supply and demand of human resources}

\subsection{Empirical analysis on prediction of supply and demand of human resources}

This article takes the total number of employees in an enterprise from 2006 to 2013 as the empirical analysis data for the prediction of the human resources demand of the enterprise. The original data is as shown in Table 1.

Table 1. List of original data with respect to the total number of employees in an enterprise from 2006 to 2013.

\begin{tabular}{|l|l|l|l|l|}
\hline Year & $t$ & $t^{2}$ & $\begin{array}{l}\text { Total number } \\
\text { of employees }\end{array}$ & $\begin{array}{l}\text { Accumulative } \\
\text { total year by year }\end{array}$ \\
\hline 2006 & 1 & 1 & 450 & 450 \\
\hline 2007 & 2 & 4 & 455 & 910 \\
\hline 2008 & 3 & 9 & 465 & 1395 \\
\hline 2009 & 4 & 16 & 480 & 1920 \\
\hline 2010 & 5 & 25 & 485 & 2425 \\
\hline 2011 & 6 & 36 & 490 & 2940 \\
\hline 2012 & 7 & 49 & 510 & 3570 \\
\hline 2013 & 8 & 64 & 525 & 4200 \\
\hline Total & 36 & 204 & 3860 & 17810 \\
\hline
\end{tabular}

According to the data in Table 1, we can obtain the scatter diagram of the total number of employees varying with $\mathrm{t}$, as shown in Figure 1.

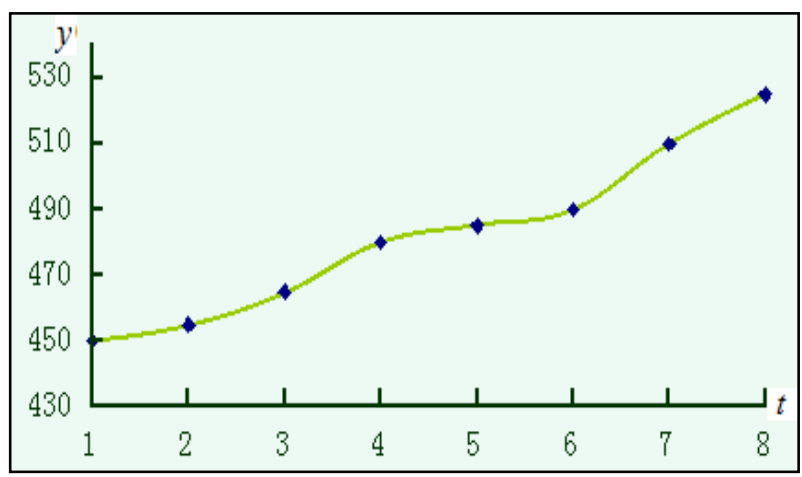

Figure 1. Scatter diagram of the total number of employees varying with $t$.

The equation obtained using linear trend equation fitting is as shown in formula (15):

$$
y=10.476 \cdot t+435.36
$$

Substitute $t=9$ into formula (15), and we can get the total staff number of 2014, namely this year. The result is 529.644, 530 after rounding, which means the actual human demand of the company in 2014 is 530.

\subsection{Empirical analysis on prediction of supply of human resources}

This article takes the data of an enterprise from 2011 to 2013 as an example to conduct empirical analysis on Markoff prediction for the supply of human resource. In order to study the personnel changes in each position conveniently, the positions will be divided into administration, marketing, technology and worker, and use the data in 2011-2013 to calculate the average probability of the internal flow of workers, expecting to predict the post outflow in 2014, namely this year. In order to improve the personnel allocation in each post, enterprises need to conduct the prediction of supply according to the post outflow. Use Markoff prediction model to conduct empirical analysis. The state transfer of all personnel in the company from 2011 to 2013 is shown in Table 2. 
Table 2. List of the state transfer of all personnel in a company from 2011 to 2013.

\begin{tabular}{|c|c|c|c|c|c|c|c|}
\hline Year & Post type & Administration & Marketing & Technology & Worker & Outflow & $\begin{array}{l}\text { Total number } \\
\text { of employees }\end{array}$ \\
\hline \multirow{4}{*}{2011} & Administration & 32 & 0 & 1 & 0 & 1 & \multirow{4}{*}{490} \\
\hline & Marketing & 5 & 56 & 3 & 0 & 11 & \\
\hline & Technology & 5 & 36 & 205 & 0 & 20 & \\
\hline & Worker & 0 & 2 & 3 & 87 & 23 & \\
\hline \multirow{4}{*}{2012} & Administration & 32 & 1 & 2 & 0 & 2 & \multirow{4}{*}{510} \\
\hline & Marketing & 3 & 69 & 2 & 0 & 8 & \\
\hline & Technology & 6 & 35 & 220 & 0 & 22 & \\
\hline & Worker & 0 & 3 & 2 & 85 & 18 & \\
\hline \multirow{4}{*}{2013} & Administration & 35 & 1 & 1 & 0 & 2 & \multirow{4}{*}{525} \\
\hline & Marketing & 5 & 78 & 1 & 0 & 12 & \\
\hline & Technology & 5 & 23 & 237 & 0 & 19 & \\
\hline & Worker & 0 & 3 & 2 & 84 & 17 & \\
\hline
\end{tabular}

According to the data in Table 2, we can obtain the personnel change matrix as shown in formula (16), which is obtained by the percentage of mean flow for each post:

$$
\mathbf{P}(1)=\left[\begin{array}{lllll}
0.90 & 0.02 & 0.04 & 0.00 & 0.04 \\
0.05 & 0.80 & 0.02 & 0.00 & 0.12 \\
0.02 & 0.11 & 0.79 & 0.00 & 0.07 \\
0.00 & 0.02 & 0.02 & 0.78 & 0.18
\end{array}\right]
$$

Dot-multiply the number vector in each department in $2013, \mathbf{S}(1)=\left[\begin{array}{llll}39 & 96 & 284 & 106\end{array}\right]$, to the average probability matrix shown in formula (16), and we can get the number in 2014. The result is:

$\mathbf{S}(2)=\left[\begin{array}{llll}45.58 & 110.94 & 229.96 & 82.68\end{array}\right]=\left[\begin{array}{llll}46 & 111 & 230 & 83\end{array}\right]$

Therefore, the total number of internal supply of this enterprise in 2014 is 452 , and the actual demand is 530 . So recruitment of 78 employees from society is required in 2014 .

\section{Conclusion}

This paper first analyzes the factors affecting the supply and demand of human resources, elaborated four kinds of factors affecting human resource demand microscopically and macroscopically, elaborated four kinds of factors affecting human resource demand in external and internal factors, aiming at exploring the reasonable forecasting model of supply and demand and making a contribution to the enterprise's human resources balance.

Then, it detailedly describes the prediction of human resource demand of trend equation fitting model and the predictions of the human resource supply of Markoff model, which provide a theoretical basis for the design and implementation of algorithm

At last, it uses the total number of employees in an enterprise from 2006 to 2013, and incorporates the linear model of trend equation fitting method to predict the act- ual number of demand human resources for this enterprise in 2014. And use the date of change in the number of personnel in four positions from 2011 to 2013 and incorporate the Markoff model to predict the number of internal supply of human resources of this enterprise in 2014, and finally, by comparing the actual demand and data of internal supply, the number of employees required to be recruited from the society in 2014 is obtained, which verifies the feasibility of the algorithm and meanwhile provides a theoretical reference for optimization of the allocation of human resources for enterprises.

\section{References}

1. Lai Xianghui. Research and application of planning model of enterprise strategic human resource [J]. Modern Economic Information, 2013:60-61.

2. Zhang Ning et al. Dynamic prediction and decision support system for supply and demand of human resources [J] Journal of Chifeng University, 2013, 29(8):30-32.

3. Li Suping et al. The Innovation and practice of prediction model of human resources demand in the power grid enterprise [J]. Chinese Power Education, 2013:140-142.

4. Cai Wenling. Forecast and balance of supply and demand of human resource [J]. Guide to Business, 2013(14):152.

5. Pan Zhu. Prediction and analysis of human re-source demand of China's enterprises based on BP neural network [J]. Foreign Trade and Economics, 2013(1): $133-135$.

6. Guo Hui. Ideas in the forecast of trend equation fitting in human resources demand and analysis of its case [J]. Journal of Langfang Normal College 2014, 14(1):98-102.

7. Wu Jing et al. Markoff model and its application in drug economic forecasting $[\mathrm{J}]$. Chinese Pharmacy, 2005, 16(14):1049-1050. 